\title{
OS NOVOS ACAMPAMENTOS (WÃRE) KAINGANG NA CIDADE DE LONDRINA: mudança e persistência numa sociedade Jê*
}

\section{Kimiye Tommasino}

Professora do Depto. de Ciências Sociais da Universidade Estadual de Londrina; Doutora em Antropologia Social pela Universidade de São Paulo.

\begin{abstract}
Este artigo analisa os acampamentos provisórios que os Kaingang da Área Indígena Apucarana passaram a fazer na cidade de Londrina. Instalados em barracas de lona, as famílias kaingang passam de dez a quinze dias vendendo artesanato de taquara - cestos de vários tamanhos e formas, peneiras - nas ruas da cidade. Muitas pessoas londrinenses passaram a reclamar da presença indígena na cidade principalmente quando vêm em grande quantidade e chegam a instalar dezenas de barracas de lona nos terrenos baldios da cidade. Este artigo teve como objetivo compreender as razões do deslocamento dos índios para a zona urbana de Londrina e ao mesmo tempo analisar o modo como eles (re)produzem um espaço kaingang, conforme seus costumes tradicionais. Tendo sido no passado, toda a região do médio Tibagi, território kaingang, pode-se afirmar que os Kaingang atuais, vivendo de modo precário nas reservas, encontram na venda do artesanato, uma forma de (re)territorialização em espaços hoje ocupados por brancos.
\end{abstract}

Palavras-chave: Kaingang; comércio; (re)territorialização.

\section{(EPÍGRAFE)}

$\pi$

u tinha muitas criações.

Mas agora não tem mais.

Eu tinha muitas criações de gado que viviam nos matos, que são as antas.

Mas agora não tem mais.

Então agora não tem mais nada para comer.

Por isso eu estou vendendo os balaios, para eu sobreviver.

Aqui tinham muitas árvores, matos, palmitos.

Mas agora não tem mais palmitos.

Eu tinha muita alimentação no mato.

Mas agora não tem mais.

Agora tem muitas criações de gado nestes pastos.

Mas eu não gosto da carne nem das gorduras deles.

Essa noite eu sonhei que comia carne de anta.
Era gostosa.

Ela estava macia.

Mas naquela hora eu acordei.

Então eu disse: por que eu sonhei desta maneira?

Eu disse para mim mesma.

Eles cavucavam a terra e faziam buraco.

Dentro do buraco eles faziam fogo e jogavam pedras.

Logo que as pedras ficavam com a cor da brasa, eles faziam em cima umas grades de varotes e depois forravam muito bem com as folhas de palmeiras.

Depois eles colocavam as carnes de anta $e$ enterravam.

No outro dia eles abriam. E as carnes ficava bem molezinhas.

Nós comíamos junto com o emi.

Farinha de pinhão também.

Quando tinha bastante pinheiros aqui.

A farinha de pinhão era muito gostosa de comer 
com a carne de anta.

Então hoje eu tenho vontade de comer de novo.

Por isso eu sonhei.

(Mulher kaingang, 70 anos aproximados; Toldo Barreiro, Posto Indígena Apucarana, inverno de 1990)

Os Kaingang formam uma das nações indígenas de maior contingente no Brasil. Calcula-se que são cerca de 20 mil pessoas espalhadas nos planaltos dos estados de São Paulo, Paraná, Santa Catarina e Rio Grande do Sul. No Paraná vivem mais de 8 mil. Junto com os Xokléng de Santa Catarina, constituem os Jê meridionais.

Até o século passado, os índios dos atuais municípios de Londrina, Ortigueira e São Jerônimo da Serra formavam uma única sociedade que dominava um território contínuo que abrangia as terras da bacia do Tibagi. Com as sucessivas expropriações de suas terras pelos colonizadores e pelo próprio Estado, os Kaingang vivem hoje ilhados em cinco reservas: Posto Apucarana (município de Tamarana), Posto Barão de Antonina e Posto São Jerônimo (município de São Jerônimo da Serra), Posto Queimadas e Posto Natingui (município de Ortigueira).

A situação de contato engendrou transformações profundas no modo de vida kaingang: destruiu as bases materiais de produção e reprodução social, alterou seus padrões tradicionais de abastecimento e, conseqüentemente, toda sua organização social sofreu mutações e adaptações no novo contexto histórico. Este texto pretende refletir sobre alguns aspectos dessa experiência histórica dos Kaingang da bacia do Tibagi.

\section{O MODO DE VIDA DOS CAÇADORES-COLETORES- AGRICULTORES KAINGANG}

Os Kaingang são tradicionalmente caçadores-coletores. A agricultura também era praticada no espaço entre a aldeia e as matas e era praticada em pequena escala nas encostas de morros.

$\mathrm{Na}$ região de campos faziam seus alojamentos fixos que chamam emã (ou jemã). Faziam também acampamentos temporários, wãre, nas florestas e beiras de rio para se abrigarem nos meses em que caçavam ou pescavam. Os deslocamentos eram feitos por grupos de parentesco de modo que sempre havia grupos no emã e outros no wãre. Esta forma de ocupação e deslocamento dentro de um território contínuo e delimitado, impõe, em nosso entendimento, uma rediscussão da classificação dos Kaingang como sociedade nômade. ${ }^{1}$ Parece necessário e possível hoje, uma discussão interdisciplinar específica para analisar esta questão. A nossa pesquisa parece apontar para a não pertinência da classificação como povo nômade embora a mobilidade espacial seja uma característica cultural dessa sociedade.

A pesca de pari, uma armadilha feita de pedras e esteira de taquara, era (e continua sendo) praticada na vazante dos rios. Armavam então um wãre e lá permaneciam por alguns meses. Nesses pari coletavam grande quantidade de peixes que eram consumidos, parte no wãre, durante os meses de permanência do grupo, e parte era seca ao sol para consumirem quando retornavam ao emã.

A caça também implicava o deslocamento dos grupos de parentesco durante semanas e até meses nas matas e, conseqüientemente, na construção de wãre.

A agricultura era praticada nos terrenos altos, nas bordas das matas e encostas de morros. Plantavam milho pururuca, abóbora, amendoim e feijão vara.

Até os anos 40 e 50 deste século, praticaram esses deslocamentos no interior de seus vastos territórios, quando ainda dispunham dos recursos florestais.

\section{A CONQUISTA DOS TERRITÓRIOS INDÍGENAS E SUAS CONSEQÜÊNCIAS}

A conquista dos Kaingang e seus territórios no Paraná teve início em 1770 com a ocupação dos campos de Guarapuava e Palmas. Apesar da resistência, em 1930 praticamente todos os grupos kaingang já estavam conquistados e aldeados.

Quando passaram a ser objeto de pacificação, os sertanistas e prepostos do Governo imperial prometeram aos índios que nada lhes faltaria e teriam toda a proteção e segurança caso aceitassem fazer as pazes e se aldeassem. Todo o processo de atração e convencimento ao aldeamento foi obtida através da distribuição de produtos que os índios desconheciam: roupas, cobertores, miçangas, espelhos, instrumentos de ferro como machado, faca, serrote, objetos que os deixaram impressionados. Durante mais de um século os Kaingang receberam esses "presentes" e acreditaram que os chefes brancos fossem generosos tal como preconiza o modelo de chefia indígena.

Um a um os grupos locais foram se aldeando em áreas delimitadas pelo Estado. Os grupos resistentes foram perseguidos pelos grupos dos caciques cooptados pelos brancos praticando ataques de surpresa conhecidos como correrias. Quando os grupos arredios não tinham mais para onde se refugiar, aceitaram viver em aldeamentos administrados pelos diretores, missionários ou civis.

O primeiro grupo do Tibagi aldeou-se em 1859 com a criação do Aldeamento São Jerônimo. O último grupo dos Coroados Bravos que vivia na região dos rios Laranjinha e Cinzas rendeu-se em 1930.

É importante enfatizar a eficácia dessa estratégia a distribuição de presentes e promessa de proteção - porque na cultura kaingang a generosidade é o valor mais elevado e era esta qualidade que conferia prestígio político aos caciques ou Pai-bang. Telêmaco Borba que conviveu com os Kaingang do Paraná desde 1863, registrou o seguinte:

Geralmente os caciques e ainda os que mais trabaIham, são os que menos objectos teem, pois é de re- 
gra entre essa gente, que nunca se deve negar o que é pedido; e uma das maiores injúrias que se lhes pode atribuir é chamal-os de pouco liberais, - deicamá - É gente de caracter altaneiro e independente que não presta obediencia a ninguem; e só por meio de dadivas e boas maneiras se póde delles conseguir alguma obediencia. (Borba, 1908:7)

Desde que a pacificação se iniciou, os Kaingang passaram a ser recrutados como mão de obra nos diversos trabalhos exigidos no processo de implantação da nova sociedade. Trabalharam como guias, mateiros, intérpretes nas expedições de reconhecimento e pacificação, e em todas as tarefas braçais exigidas nos aldeamentos. Foram os Kaingang de São Jerônimo que construíram a Estrada do Cerne, ainda no século passado. Foi a produção dos aldeamentos indígenas que abasteceram as expedições de reconhecimento da bacia do Tibagi para a abertura de uma ligação entre o Rio de Janeiro e o Mato Grosso. Quer dizer, os Kaingang ajudaram a construir as bases para a nova ocupação que se deu a partir de 1850 na região do Tibagi.

\section{DEPENDÊNCIA, PAUPERIZAÇÃO E ESTRATÉGIAS DE SOBREVIVẾNCIA}

Quando não havia mais terras indígenas para serem confiscadas, o Governo mudou o tratamento dado aos índios. A "generosidade" desapareceu, os diretores dos aldeamentos passaram a incentivá-los a passarem a viver com recursos próprios. Só que os seus recursos vinham das florestas e campos que tinham sido apropriados pelos colonos brancos. Os seus territórios de caça e coleta sofreram mutações profundas. Viraram cidades, cafezais, pastagens. Como então sobreviver nesse novo universo comandado pelos Paibang (chefes) brancos?

A contratação de trabalhadores indígenas teve início quando os primeiros exploradores começaram a vasculhar as suas terras, a partir do século XVII. O artesanato feito de taquara, confeccionado pelas mulheres para uso, também começou a ser vendido esporadicamente, quando as primeiras povoações surgiram. Portanto, foram atividades novas iniciadas pelas avós dos Kaingang contemporâneos.

Expropriados de seus territórios tradicionais, os Kaingang foram obrigados a adotar novos padrões impostos pela sociedade dominante. A única alternativa para sobreviver era adaptarem-se às novas condições materiais de vida. Tornaram-se agricultores de subsistência, assalariados e passaram a vender seu artesanato nos distritos e nas cidades.

Os homens foram forçados a se adaptar às novas relações de trabalho. Quase todos eles já foram arrendatários, meeiros, empreiteiros, camaradas, peões. Entre 1989 e final de 1995, os Kaingang passaram a trabalhar como cortadores de cana assalariados nas usinas de álcool e açúcar do Mato Grosso do Sul.

Dentro das reservas, os índios fazem suas roças. Mas a produção nunca é suficiente e uma das razões que explica o fracasso dos projetos econômicos das reservas é que o indigenismo oficial nunca levou em conta as especificidades culturais dos índios.

É importante ressaltar que mesmo vivendo hoje nas condições impostas pela sociedade nacional, a proletarização dos índios não significou a sua dissolução social e cultural tal como previam algumas teorias antropológicas do passado. Apesar da miséria e dependência produzidas pela experiência de dominação, os Kaingang continuam se reproduzindo enquanto grupo etnicamente diferenciado.

Por outro lado, as recentes teorias sobre a situação de contato e mudança sociocultural têm trazido novos referenciais que procuram explicar de forma mais satisfatória as realidades contemporâneas dos povos indígenas.

Neste artigo estamos utilizando basicamente a teoria de Sahlins que está sintetizada da seguinte forma:

A história é ordenada culturalmente de diferentes modos nas diversas sociedades, de acordo com os esquemas de significação das coisas. O contrário também é verdadeiro: esquemas culturais são ordenados historicamente porque, em maior ou menor grau, os significados são reavaliados quando realizados na prática. A síntese desses contrários desdobra-se nas ações criativas dos sujeitos históricos, ou seja, as pessoas envolvidas. Porque, por um lado, as pessoas organizam seus projetos e dão sentido aos objetos partindo das compreensões preexistentes da ordem cultural. Nesses termos, a cultura é historicamente reproduzida na ação. (...) Por outro lado, entretanto, como as circunstâncias contingentes da ação não se conformam necessariamente aos significados que lhes são atribuídos por grupos específicos, sabe-se que os homens criativamente repensam seus esquemas convencionais. É nesses ter mos que a cultura é alterada historicamente na ação. Poderíamos até falar de "transformação estrutural", pois a alteração de alguns sentidos muda a relação de posição entre as categorias culturais, havendo assim uma "mudança sistêmica. (Sahlins, 90:7)

\section{O ARTESANATO MERCANTIL EM LONDRINA E REGIÃO}

No processo de (re)territorialização no mundo dos brancos, uma das alternativas econômicas para os Kaingang tem sido a produção do artesanato mercantil. As necessidades hoje são quase infinitas e o dinheiro é um artigo sempre muito escasso. A venda do artesanato tem sido, cada vez mais, a alternativa mais importante de se obter dinheiro imediato para a compra dos produtos industrializados, dos quais dependem: óleo, açúcar, sal, farinha de milho, carne; roupas, calçados, utensílios domésticos e remédios.

Londrina tornou-se o principal centro consumidor das mercadorias kaingang e, ao mesmo tempo, fornecedor de serviços e produtos imprescindíveis à sua sobrevivência. É aqui, também, que vêm buscar ajuda da FUNAI-Fundação Nacional do Índio, na sede da administração regional. Aqui fazem os tratamentos médicos. 
Nas últimas décadas, quanto mais os Kaingang subordinam-se ao mercado, tanto mais pobres ficam. As roças familiares são insuficientes, o salário como assalariados rurais é irrisório, as condições de vida sub-humanas. O resultado é uma miséria crescente, aumento de doenças próprias do terceiro mundo: doenças do aparelho respiratório, diarréias, tuberculose. A mortalidade infantil é alta e o alcoolismo que acomete jovens e adultos tem piorado as condições gerais de vida.

\section{A CIDADE DE LONDRINA E OS ACAMPAMENTOS INDÍGENAS}

Os Kaingang freqüentavam a região de Londrina quando a cidade não existia nem em sonhos. Esta era parte do seu território de caça, coleta e pesca. No Manuscrito deixado por Frei Timótheo, primeiro diretor do Aldeamento São Pedro, relata o missionário capuchinho que no dia 24 de julho de 1859 encontrou no rio Três Bocas, 40 índios kaingang pescando num pari, recebendo a ele e ao Comandante da Colônia do Jataí "com grande alegria". De nossa parte temos depoimentos dos Kaingang mais idosos do Posto Indígena Apucarana que também confirmam que caçavam nestas terras.

A venda de artesanato é uma atividade que foi iniciada desde que surgiram as primeiras vilas, pelas suas mães e avós. Foi um espaço desenvolvido lentamente, à medida em que surgiam as novas necessidades. Também foi sendo aperfeiçoado pela própria dinâmica da prática comercial.

Dona Dolores lembra que, quando criança, se dirigia a Londrina para vender balaios e peneiras quando lá havia apenas 5 casas. Só seu pai falava um pouco o português e iam a cavalo. O cesto então era de outro modelo, seguia o padrão tradicional: não tinha pés, o fundo era arredondado e ia direto ao chão. Os próprios compradores brancos, que em geral eram as mulheres, não queriam que o cesto ficasse no chão por causa da umidade. Inventaram então de pôr os pezinhos que acabou se tornando o padrão atual, mais adequado à exigência do mercado. Também começaram a fazer de novos tamanhos, para atender aos pedidos: para colocar roupas, para colocar frutas, como simples enfeites ou souvenir. Descobriram que os consumidores gostavam de cores vivas, passaram a usar desenhos formados por algumas tiras pintadas com anilina. Hoje a presença de mulheres indígenas vendendo seus balaios nas ruas faz parte da paisagem londrinense.

Conforme sua tradição, deslocam-se em grupos de parentesco. É necessário uma equipe para auxiliar no transporte das mercadorias, no cuidado do acampamento e pelo menos um que saiba o português.

Pressionados pelas coerções próprias da atual conjuntura, engendrou-se o comércio indígena. Através desse comércio, os Kaingang do Posto Apucarana passaram a construir os novos wãre, agora na zona urbana. Expropriados de seu habitat natural, os índios recriaram um espaço kaingang no mundo dominado pelos brancos, seguindo um padrão préexistente. Mesmo tendo alterado seu modo de vida, os Kaingang não perderam seu ethos caçador-coletor.
A sociedade kaingang continua reproduzindo uma cultura específica e distinta da ocidental, apesar das aparências ocidentalizadas. A cultura tradicional, herdada de seus antepassados, teve de ser trabalhada, adaptada, reformulada, modificada, repensada, inventada, de forma a enfrentar a nova conjuntura histórica. Pode-se dizer que os Kaingang, na prática, tiveram de adotar padrões novos, padrões esses impostos pelo colonizador. Mas como bem adverte Le Goff,

A história caminha mais ou menos depressa, porém as forças profundas da história só atuam e se deixam apreender no longo tempo.

(...)

A história do curto prazo é incapaz de apreender e explicar as permanências e as mudanças. (...)

Portanto, é preciso estudar o que muda lentamente e o que se chama, desde há alguns decênios, de estruturas; (...) (Le Goff, 93:45)

Portanto, o modo de vida kaingang foi modificado por contingências externas mas a história kaingang é provida de uma historicidade própria. Porque, como diz Sahlins,

As improvisações (reavaliações funcionais) dependem das possibilidades dadas de significação, mesmo porque, de outro modo, seriam ininteligíveis e incomunicáveis. Daí o empírico não ser apenas conhecido enquanto tal, mas enquanto uma significação culturalmente relevante, e o antigo sistema é projetado adiante sob novas formas. Segue-se daí que ordens culturais diversas tenham modos próprios de produção histórica.

Culturas diferentes, historicidades diferentes. (...) (Sahlins, 90:11)

A partir desse referencial teórico, pode-se afirmar que os acampamentos de hoje são uma reedição, histórica e culturalmente atualizada, de uma antiga tradição kaingang. Os novos acampamentos provisórios surgem dentro do presente contexto que os obriga a saírem das reservas para obtenção de víveres, objetos de uso e serviços no território dominado e modificado pelo branco. Se antes caçavam e coletavam nas florestas, hoje o fazem na cidade ou emãbang, na sua língua.

Nos wãre do passado os Kaingang se realizavam como homens livres, nos wãre de Londrina são alienados de sua produção e de si mesmos e expressam a sua subordinação ao sistema dominante. Mas interessa-nos mostrar que, mesmo submetidos, os Kaingang desenvolveram estratégias de resistência cultural e política que lhes permitiram manter a sua especificidade étnica.

Observando a estrutura dos acampamentos, percebemos que os índios recriam, temporariamente, um espaço social tipicamente kaingang: deslocam-se em grupos de parentesco, cada qual instala sua barraca e lá permanece por cerca de 10 ou 15 dias. Tal como faziam antes (e ainda fazem) nas matas e beira de rios, trazem os equipamentos básicos para a permanência provisória: roupas, panelas, animais de estimação. A cozinha é improvisada na parte externa da barraca, os 
produtos para comércio são expostos dependurados nas árvores das ruas, em frente ao acampamento. Dentro da barraca, ajeitam as mercadorias, as roupas de uso, forram o chão onde dormem. Não se incomodam de dormirem no chão, pois consideram que "vida de índio é assim mesmo". Lembram-se que quando crianças dormiam todos no chão sobre folhas de samambaia, com os pés voltados para o fogo que ficava aceso a noite toda. Por paradoxal que pareça, para os mais velhos, estar num acampamento em Londrina produz uma sensação de retorno ao tempo antigo. O que incomoda os índios acampados na cidade é o barulho dos carros e da cidade.

O importante nesses deslocamentos é que os Kaingang ao mesmo tempo em que recriam seu ambiente na cidade, conseguem arrecadar a renda necessária para o sustento da família.

\section{VENDENDO MAIS PARA FAZER FESTAS}

Mas há outros elementos importantes que necessitam ser considerados nesta questão. Podemos observar que em algumas épocas, os acampamentos ficam maiores porque aumenta o número de famílias vendendo suas mercadorias ou arrecadando doações. Isso tem uma explicação que envolve elementos tanto de ordem histórica quanto cultural.

No passado, a vida religiosa kaingang tinha como centros de elaboração cultural, o culto aos mortos (kikikoi) e a organização da comunidade em grupos de parentesco. A dança era uma atividade de grande importância e estava ligada ao desenvolvimento especial do culto aos mortos, mais conhecido como festa do kiki. Os Kaingang tomavam então a bebida sagrada ( $k i k i$ ) e executavam as cerimônias dançando em volta do fogo. Toda a dança cerimonial era acompanhada de cantos sagrados, sons de flauta e chocalho e os dançadores formavam círculos de acordo com o grupo de pintura a que pertenciam. (Schaden, 59)

Cada grupo local fazia ainda outras festas de caráter profano e mais ligadas às atividades econômicas. A essas festas ele chamam festa do êmi (bolo de milho azedo).

Há cerca de 50 anos os Kaingang desta região deixaram de fazer a festa do kiki mas adotaram as festas introduzidas pelos diretores e missionários dos aldeamentos. Desenvolveram então o gosto pelos bailes acompanhados por música de sanfona e principalmente para as músicas e danças de origem gaúcha como o vanerão, xote e bugio.

Mas neste processo, os valores tradicionais não desapareceram. Os significados simbólicos presentes nas festas tradicionais migraram para as festas modernas. Assim se explica a grande importância que dão às comemorações que fazem na reserva: Dia do Índio, da Independência, Páscoa, Natal, Ano Novo. Nessas ocasiões, toda a comunidade organiza a festa que, para ser completa, deve ter comida em abundância, jogo de futebol e baile.

É preciso então entender porque nas semanas que antecedem uma festa, os Kaingang começam os preparativos para que ela seja bem sucedida. Se no passado dirigiamse para as florestas e rios em busca de alimentos que seriam consumidos ritualmente, agora se dirigem para as suas roças, onde colhem milho, arroz, batata doce, mandioca; e também vão vender balaios e peneiras na cidade, onde completam a abastecimento.

O aumento dos acampamentos na cidade, então, é notável. Quando dependiam só dos recursos da floresta, a festa do kiki era feita nos meses de inverno, quando havia pinhão em abundância e quando as roças de milho estavam maduras. Agora as festas não obedecem ao calendário ecológico de modo que a maior parte dos alimentos têm de ser comprados na cidade. Além disso, os índios gostam de estar bem vestidos e calçados para o baile. Vestir-se com roupas especiais de festa tem raízes na tradição kaingang: BiggWither registrou e ilustrou como eles se cobriam com um manto de penas de aves no século passado. (Bigg-Wither, 1974:389) De outro lado, o contato com camponeses nacionais reforçou a importância da roupa especial (em oposição ao traje de trabalho) para as ocasiões cerimoniais e festivas.

Agora, o que mais realiza os Kaingang nestas festas é a abundância de comida porque é através da comensalidade que se efetiva toda a sociabilidade entre os parentes. $\mathrm{O}$ valor moral mais elevado nas sociedades indígenas, como afirmamos, é a generosidade e esta se manifesta principalmente na distribuição de alimentos. Borba observou que os Kaingang:

São muito francos do que teem em seos ranchos; quando alguem chega a elles, a primeira cousa que fazem é perguntar se tem fome; nos dias de abundancia nem isso fazem; sem nada dizer vão pondo deante da pessoa a comida dizendo - coma - (acó); nunca negam a comida que se lhes pede; do pouco que teem comem juntos. (Borba, 1908:14)

Nas semanas que antecedem o Dia do Índio, Páscoa, Natal e Ano Novo, quase todos os Kaingang acampam em Londrina. Nessas ocasiões, a imprensa local registra várias reclamações de citadinos que alegam estarem os índios sujando áreas públicas e invadindo a cidade.

Ocorre que na época das festividades nacionais, introduzidas nas aldeias pelos missionários e indigenistas, os Kaingang sabem que os Pai-bang brancos ficam "generosos" e distribuem cestas de alimentos e brinquedos. A "coleta" ganha, assim, possibilidades de maior sucesso. Mas precisam vender muito artesanato para comprar roupa nova, sapato e muita comida, para comemoração da data na comunidade com uma grande festa. Comendo e bebendo muito. $\mathrm{E}$ dançando a noite toda, até amanhecer: vanerão, xote e bugio. Ao som da sanfona, do violão, da guitarra e da bateria.

\section{CONSIDERAÇÕES FINAIS}

Este ensaio sobre os acampamentos kaingang nos encaminhou, necessariamente, a percorrer vários aspectos da vida social deste povo. Procuramos levar a análise para além das transformações histórico-estruturais a fim de identificar alguns elementos da resistência cultural e social permanentes neste processo. 
Mostramos como uma sociedade se moveu no tempo apreendendo uma dinâmica que procurou evidenciar a historicidade de um grupo étnico.

Enfim, pretendemos reafirmar que os Kaingang foram e continuam sendo sujeitos ativos de sua história. Não perderam a sua cultura e identidade mas a transformaram e reelaboraram para fazer frente às pressões externas. Os Kaingang de hoje sincretizaram na cultura atual elementos da tradição e da modernidade, sem abdicarem, contudo, de sua identidade própria. Se já não podem viver como seus antepassados, também não se tornaram culturalmente ocidentais. Eles continuam reproduzindo-se com Kaingang-pé (índios legítimos).

\section{NOTAS}

- Este texto, em sua versão original, foi apresentado na V Reunião da ABA(Merco)Sul, em Tramandaí-RS em setembro de 1995. A construção e próxima inauguração, pela Prefeitura Municipal de Londrina, de um Referencial Kaingang e Centro Cultural para atender as famílias que vêm vender seu artesanato na cidade, torna importante a divulgação deste artigo.

1 Na ABA-Sul de Florianópolis, em 1993, apresentamos um trabalho sobre concepção de território kaingang e pudemos verificar que a expansão dos mesmos para os estados do Sul não implicou abandono dos territórios anteriores. Ao contrário, um grupo sempre permaneceu no local de origem e outro, o grupo dissidente, é que ocupava uma nova área, constituindo um novo território e assim sucessivamente. Explicase, dessa forma, porque os Kaingang se espalharam por todo o Brasi] meridional.

\section{BIBLIOGRAFIA CONSULTADA}

AMBROSETTI, Juan B. Kaingángues de San Pedro (Misiones). Revista del Jardin Zoológico. Tomo II, Ent. 10. Buenos Aires, 1985.

BALDUS, Herbert. Ensaios de etnologia brasileira. São Paulo: Brasiliana, 1937.

BARBOSA, L. B. H. A pacificação dos Cangangues paulistas. Hábitos, costumes e instituições desses índios. Rio de Janeiro, 1931.

BIGG-WITHER, T. Novo caminho no Brasil meridional: a província do Paraná. Três anos em suas florestas e campos 1872/1875. Curitiba: Livraria José Olympio Editora/Universidade Federal do Paraná, 1974.

BORBA, Telêmaco. Actualidade indígena. Paraná-Brazil. Coritiba: Typ. e Lytog. a vapor Impressora Paranaense, 1908.

BOUTIN, Leônidas. Colônias indígenas na província do Paraná. Boletim do Instituto Histórico, Geográfico e Etnológico Paranaense. Volume XXXVI. Curitiba, 1979.

HANKE, Wanda. Ensayo de uma gramática del idioma Caingangue de los Caingangues de la Serra de Apucarana. Paraná, Brasil. Arquivo do Museu Paranaense, 1950.

LE GOFF, Jacques. A História Nova. São Paulo: Martins Fontes, 1993.

LÉVI-STRAUSS, Claude. Tristes trópicos. Martins Fontes/Portugália Editora, 1955.

SAHLINS, Marshall. Ihas de História. Rio de Janeiro: Jorge Zahar Editor, 1990.

SCHADEN, Egon. A mitologia heróica de tribos indígenas do Brasil. Rio de Janeiro: MEC, 1959. 